\title{
Endophytic fungal association via gibberellins and indole acetic acid can improve plant growth under abiotic stress: an example of Paecilomyces formosus LHL10
}

Abdul Latif Khan ${ }^{1,2}$, Muhammad Hamayun ${ }^{3}$, Sang-Mo Kang ${ }^{1}$, Yoon-Ha Kim ${ }^{1}$, Hee-Young Jung ${ }^{4}$, Joong-Hwan Lee ${ }^{5}$ and In-Jung Lee 1* $^{*}$

\begin{abstract}
Background: Endophytic fungi are little known for exogenous secretion of phytohormones and mitigation of salinity stress, which is a major limiting factor for agriculture production worldwide. Current study was designed to isolate phytohormone producing endophytic fungus from the roots of cucumber plant and identify its role in plant growth and stress tolerance under saline conditions.

Results: We isolated nine endophytic fungi from the roots of cucumber plant and screened their culture filtrates (CF) on gibberellins (GAs) deficient mutant rice cultivar Waito-C and normal GAs biosynthesis rice cultivar Dongjinbyeo. The CF of a fungal isolate $\mathrm{CSH}-6 \mathrm{H}$ significantly increased the growth of Waito-C and Dongjin-byeo seedlings as compared to control. Analysis of the CF showed presence of $G A s\left(G_{1}, G A_{3}, G A_{4}, G A_{8}, G A_{9}, G_{12}, G A_{20}\right.$ and $\mathrm{GA}_{24}$ ) and indole acetic acid. The endophyte CSH-6H was identified as a strain of Paecilomyces formosus LHL10 on the basis of phylogenetic analysis of ITS sequence similarity. Under salinity stress, P. formosus inoculation significantly enhanced cucumber shoot length and allied growth characteristics as compared to non-inoculated control plants. The hypha of $P$. formosus was also observed in the cortical and pericycle regions of the host-plant roots and was successfully re-isolated using PCR techniques. P. formosus association counteracted the adverse effects of salinity by accumulating proline and antioxidants and maintaining plant water potential. Thus the electrolytic leakage and membrane damage to the cucumber plants was reduced in the association of endophyte. Reduced content of stress responsive abscisic acid suggest lesser stress convened to endophyte-associated plants. On contrary, elevated endogenous $\mathrm{GAs}\left(\mathrm{GA}_{3}, \mathrm{GA}_{4}, \mathrm{GA}_{12}\right.$ and $\left.\mathrm{GA}_{20}\right)$ contents in endophyte-associated cucumber plants evidenced salinity stress modulation.
\end{abstract}

Conclusion: The results reveal that mutualistic interactions of phytohormones secreting endophytic fungi can ameliorate host plant growth and alleviate adverse effects of salt stress. Such fungal strain could be used for further field trials to improve agricultural productivity under saline conditions.

Keywords: Paecilomyces formosus LHL10, Salinity, Cucumber plant growth, Gibberellins and indole acetic acid, Endogenous plant hormones

\footnotetext{
* Correspondence: ijlee@knu.ac.kr

'School of Applied Biosciences, Kyungpook National University, Daegu,

Republic of Korea

Full list of author information is available at the end of the article
} 


\section{Background}

Various crops cultivated in arid or semi-arid regions are frequently exposed to wide range of environmental stresses. Among these, salinity severely affects plant growth and metabolism and hence results in reduced biomass production. Plants have the capability to cope with these stresses through many signal transduction pathways adjusting their metabolism [1-3]. These adjustments range from changes in ionic/osmotic levels, stomatal closure to changes in phytohormones and secondary metabolites [4]. Sodium ion toxicity trigger the formation of reactive oxygen species (ROS) such as superoxide $\left(\mathrm{O}_{2}{ }^{-}\right)$, hydrogen peroxide $\left(\mathrm{H}_{2} \mathrm{O}_{2}\right)$, and hydroxyl radical $(\cdot \mathrm{OH})$ which can ultimately damage; (i) mitochondria and chloroplasts, (ii) water use efficiency, (iii) photosynthesis, and (iv) nutrients uptake whilst disrupting cellular structures $[1,4]$. To avoid oxidative damage, plants adapt by de novo synthesis of organic compatible solutes acting as osmolytes. Osmolytes like proline serve a free-radical scavenger stabilize subcellular structures and buffer cellular redox potential under stress [5]. In counteracting oxidative stress antioxidant molecules are also involved as defence strategy.

Symbioses with beneficial fungi can ameliorate plant growth and its physiological status [6]. Endophytic fungi comprise of fungal symbionts associated with plants living inside tissues without causing any disease symptoms [7-11]. Endophytes have mostly been reported for their behaviour to enhance plant growth as they influence key aspects of plant physiology and host protection against biotic and abiotic stresses $[9,10,12]$. Besides that, endophytic fungi have been known as an important source of various kinds of bioactive secondary metabolites $[8,13]$. It has been known recently that some of the strains of endophytic fungi can produce plant hormones especially gibberellins (GAs) [14]. Under extreme environmental conditions, these phytohormone producing endophytic fungi can effect the production of several secondary metabolites like flavonoids [15] along with phytohormones to help the plant to tolerate/avoid stress $[8,12,16]$. GAs are ubiquitous substances that elicit various metabolic functions required during plants' growth $[17,18]$. However, little is known about GAs production by endophytic fungi and their role in abiotic stress. Previously, various strains of fungal species including endophytes have been reported to either secrete GAs in their culture medium or have an active GAs biosynthesis pathway. Fungal species like Gibberella fujikuroi, Sphaceloma manihoticola [18], Phaeosphaeria sp., Neurospora crassa [19], Sesamum indicum [20], Phaeosphaeria sp. L487 [21], Penicillium citrinum [14], Chrysosporium pseudomerdarium [22] and Scolecobasidium tshawytschae [23], Aspergillus fumigatus [15] and Penicillium funiculosum
[16] have been reported as GAs producers. GAs along with other plant hormones like indole acetic acid (IAA) secreted by fungal endophytes can improve plant growth and crop productivity $[24,25]$.

Aim of the present study was to identify plant hormone (GAs and IAA) secreting endophytic fungal strain and assess its role in host-plant physiology under saline conditions. For this purpose, isolated endophytic fungal strains were initially screened on GAs deficient mutant rice culti$\operatorname{var}$ (Waito-C) and GAs cultivar (Dongjin-byeo) seedlings to differentiate between plant growth promoting/inhibiting and plant hormones producing strain. The best fungal strain identified was examined for its potential role in plant growth under sodium chloride $(\mathrm{NaCl})$ induced salinity stress. To elucidate the mitigation of oxidative stress imposed by $\mathrm{NaCl}$, photosynthesis rate, stomatal conductance, transpiration rate, relative water content (RWC), electrolytic leakage (EL), free proline content, nitrogen assimilation, antioxidant and lipid peroxidation were analyzed. Endogenous ABA and GAs $\left(\mathrm{GA}_{3}, \mathrm{GA}_{4}, \mathrm{GA}_{12}\right.$ and $\mathrm{GA}_{20}$ ) were quantified to understand the influence of salt stress and endophytic fungal association on the growth of cucumber plant.

\section{Materials and methods}

\section{Endophyte isolation and screening}

We collected 120 roots pieces from the field grown cucumber plants (four). Root pieces were surface sterilized with $2.5 \%$ sodium hypochlorite (30 min in shaking incubator at $120 \mathrm{rpm}$ ) and washed with autoclaved distilled water (DDW) to remove the contaminants, rhizobacteria and mycorrhizal fungi. The root pieces $(0.5 \mathrm{~cm})$ were carefully placed in petri-plates containing Hagem media $(0.5 \%$ glucose, $0.05 \% \mathrm{KH}_{2} \mathrm{PO}_{4}, 0.05 \% \mathrm{MgSO}_{4} .7 \mathrm{H}_{2} \mathrm{O}, 0.05 \%$ $\mathrm{NH}_{4} \mathrm{Cl}, 0.1 \% \mathrm{FeCl}_{3}, 80$ ppm streptomycin and 1.5\% agar; $\mathrm{pH} 5.6 \pm 0.2$ ). The sterilized roots were also imprinted on separate Hagem plates to ensure the effectiveness of surface sterilization [14]. Endophytic fungi were isolated according to the method described by Khan et al [14] and Hamayun et al. [22,23]. The newly emerged fungal spots from the roots were isolated and grown on potatodextrose agar (PDA) medium under sterilized conditions [14]. Total nine different fungal strains were isolated and grown on PDA media. These strains were inoculated in Czapek broth $(50 \mathrm{ml} ; 1 \%$ glucose, $1 \%$ peptone, $0.05 \% \mathrm{KCl}, 0.05 \%$ $\mathrm{MgSO}_{4} .7 \mathrm{H}_{2} \mathrm{O}$, and $0.001 \% \mathrm{FeSO}_{4} .7 \mathrm{H}_{2} \mathrm{O} ; \mathrm{pH} 7.3 \pm 0.2$ ) and grown for seven days (shaking incubator $-120 \mathrm{rpm}$; temperature $30^{\circ} \mathrm{C}$ ) to separate liquid culture medium and fungal mycelia (centrifugation $2500 x \mathrm{~g}$ at $4^{\circ} \mathrm{C}$ for $15 \mathrm{~min}$ ). The culture medium (culture filtrate-CF, $50 \mathrm{ml}$ ) and mycelium $(5.4 \mathrm{gm})$ were immediately shifted to $-70^{\circ} \mathrm{C}$ freezer and then freeze-dried (Virtis Freeze Dryer, Gardiner, NY, USA) for 4-7 days. The lyophilized CF was diluted with 
one $\mathrm{ml}$ of autoclaved DDW, while the mycelia were used for genomic DNA extraction.

Presence or absence of plant growth promoting metabolites in fungal CF was confirmed by performing screening bioassays on gibberellins biosynthesis deficient mutant rice Waito- $C$ and normal GAs cultivar Oryza sativa L. cv. Dongjin-byeo. Waito- $C$ has dwarf phenotype while Dongjin-byeo has normal phenotype. For bioassay experiment, rice seeds were surface sterilized with $2.5 \%$ sodium hypochlorite for 30 minutes, rinsed with autoclaved DDW and then incubated for $24 \mathrm{hr}$ with 20-ppm uniconazol (except Dongjin-byeo) to obtained equally germinated seeds. Then pre-germinated Waito-C and Dongjin-byeo seeds were transferred to pots having water: agar medium $(0.8 \% \mathrm{w} / \mathrm{v})$ [14] under aseptic conditions. Both the rice cultivars were grown in growth chamber (day/night cycle: $14 \mathrm{hr}-28^{\circ} \mathrm{C} \pm$ $0.3 ; 10 \mathrm{hr}-25^{\circ} \mathrm{C} \pm 0.3$; relative humidity $70 \%$; 18 plants per treatment) for ten days. Ten micro-litter of fungal CF was applied at the apex of the rice seedlings. One week after treatment, the shoot length, chlorophyll content and shoot fresh weight were recorded and compared with negative (autoclaved DDW) and positive controls (Gibberella fujikuroi). The wild-type strain of G. fujikuroi KCCM12329, provided by the Korean Culture Center of Microorganisms, was used as positive control. Upon screening results, bioactive fungal strain $\mathrm{CSH}-6 \mathrm{H}$ was selected for further experiments and identification.

\section{Fungal DNA isolation, identification and phylogenetic analysis}

Genomic DNA was extracted from CSH-6H using standard method of Khan et al. [14]. Fungal isolate was identified by sequencing the internal transcribed region (ITS) of rDNA using universal primers: ITS-1; 5'-TCC GTA GGT GAA CCT GCG G-3' and ITS-4; 5'-TCC TCC GCT TAT TGA TAT GC-3'. The BLAST search program (http:// blast.ncbi.nlm.nih.gov) was used to compare the nucleotide sequence similarity of ITS region of related fungi. The closely related sequences obtained were aligned through CLUSTAL W using MEGA version 4.0 software [26] and a maximum parsimony tree was constructed using the same software. The bootstrap replications $(1 \mathrm{~K})$ were used as a statistical support for the nodes in the phylogenetic tree.

\section{Endophytic interactions and stress application}

Experiments were conducted with a completely randomized block design in order to assess the endophytic fungus relationship with host-plants. Experiments comprised of cucumber (Cucumis sativus L) plants with (i) fungal inoculation, (ii) without inoculation, (iii) fungal inoculation with salt stress (60 and $120 \mathrm{mM}$ ), and (iv) without inoculation and salt stress. On the basis of results obtained in Waito-C and Dongjin-byeo screening bioassay, the bioactive endophytic fungal strain $(\mathrm{CSH}-6 \mathrm{H})$ was inoculated in Czapek broth $(250 \mathrm{ml})$ as described in endophyte isolation and screening section. Similarly, cucumber seeds before sowing in autoclaved pots were surface sterilized as described earlier. The germinated seeds $\left(28^{\circ} \mathrm{C}\right.$ and relative humidity of $60 \%)$ were grown in autoclaved pots (200 g/ pot of soil at $121^{\circ} \mathrm{C}$ for $\left.90 \mathrm{~min}\right)$. The fungal mycelia and culture filtrate $(20 \mathrm{ml}$ for each pot containing ten propagules) were added to substrate composed of peat moss (13-18\%), perlite (7-11\%), coco-peat (63-68\%) and zeolite (6-8\%), with macro-nutrients present as: $\mathrm{NH}_{4^{-}} \sim 90 \mathrm{mg}$ $\mathrm{Kg}^{-1}$; $\mathrm{NO}_{3^{-}} \sim 205 \mathrm{mg} \mathrm{Kg}{ }^{-1}$; $\mathrm{P}_{2} \mathrm{O} 5 \sim 350 \mathrm{mg} \mathrm{Kg}^{-1}$ and $\mathrm{K}_{2} \mathrm{O}$ $\sim 100 \mathrm{mg} \mathrm{Kg}^{-1}$ [12-14]. The control plants only received 20 $\mathrm{ml} /$ pot of endophyte-free medium (containing $1 \%$ glucose, $1 \%$ peptone, $0.05 \% \mathrm{KCl}, 0.05 \% \mathrm{MgSO}_{4} .7 \mathrm{H}_{2} \mathrm{O}$, and $0.001 \%$ $\mathrm{FeSO}_{4} .7 \mathrm{H}_{2} \mathrm{O}$; pH $7.3 \pm 0.2$; shaking for 10 days at $30^{\circ} \mathrm{C}$ ). The endophytic fungi and cucumber plants were grown together for three weeks in growth chamber (day/night cycle: $14 \mathrm{hr}-28^{\circ} \mathrm{C} \pm 0.3 ; 10 \mathrm{hr}-25^{\circ} \mathrm{C} \pm 0.3$; relative humidity $60-65 \%$; 18 plants per treatment) and irrigated with distilled water. After three weeks, $\mathrm{NaCl}$ solution $(300 \mathrm{ml} /$ plant) was applied to cucumber plants for one week in order to assess the affect of salt stress on these plants.

The growth parameters i.e. shoot length, shoot fresh and dry weights were measured for harvested cucumber plants, while chlorophyll content of fully expanded leaves were analyzed with the help of chlorophyll meter (SPAD-502 Minolta, Japan). Dry weights were measured after drying the plants at $70^{\circ} \mathrm{C}$ for $72 \mathrm{~h}$ in oven. Total leaf area was measured with Laser Leaf Area meter (CI-203 model, CID Inc., USA). Portable photosynthesis measurement system (ADC BioScientific LCi Analyser Serial No. 31655, UK) was used to calculate the net photosynthetic rate $(\mu \mathrm{molm}$ $\left.{ }^{2} \mathrm{~s}^{-1}\right)$, transpiration rate $\left(\mathrm{mMm}^{-2} \mathrm{~s}^{-1}\right)$ and stomatal conductance $\left(\mathrm{molm}^{-2} \mathrm{~s}^{-1}\right)$ per unit leaf area of fully expanded leaves. For each measurement, readings were recorded in triplicates. For endogenous phytohormonal analysis of cucumber plants, the treated samples were immediately frozen in liquid nitrogen and kept until further use at $-70^{\circ}$ C. Samples were freezed dried in Virtis Freeze Dryer (Gardiner, NY, USA).

\section{Microscopic analysis}

Cucumber roots inoculated with $\mathrm{CSH}-6 \mathrm{H}$ were sectioned and treated with sodium hypochlorite (2.5\%) for $10 \mathrm{~min}$ for clarification. Experimental conditions were kept aseptic during analysis. Inoculated roots were treated with $20 \% \mathrm{KOH}$ for $24 \mathrm{~h}$ and rinsed with autoclaved DDW. The roots were then acidified with $10 \% \mathrm{HCl}$, stained overnight using $0.05 \% 0.1 \%$ acid fuchsin and 95\% lactic acid. Finally, the roots were destained in 95\% lactic acid for $24 \mathrm{~h}$. The roots pieces were then subjected to light microscope (Stemi SV 11 Apo, Carl Zeiss). The root parts having active colonization were 
used for re-isolation of the inoculated $\mathrm{CSH}-6 \mathrm{H}$ with the method as described earlier.

\section{RWC, EL, proline, nitrogen assimilation, antioxidant and lipid peroxidation}

Relative water content (RWC) and electrolytic leakage (EL) were measured following González and González-Vilar [27]. Free proline was estimated following Bates et al. [28]. Plant samples were oven-dried at $65^{\circ} \mathrm{C}$ and were ground to pass through $1-\mathrm{mm}$ mesh sieves and analyzed for $\mathrm{N}$ using CNS analyzer (Carlo-Erba NA1500, Carlo Erba Instruments, Milano, Italy). Antioxidant activity was measured on the basis of radical scavenging activity of 1 , 1-diphenyl-2-picrylhydrazyl (DPPH) as described Xie et al. [29]. The extent of lipid peroxidation was determined by the method of Ohkawa et al. [30]. The experiments were repeated three times.

\section{GAs extraction from fungal CF and cucumber plants}

To characterize GAs secreted in the pure fungal culture of bioactive endophyte, it was inoculated in Czapek broth $(120 \mathrm{ml})$ for 7 days at $30^{\circ} \mathrm{C}$ (shaking incubator-120 rpm) as described previously $[14,24]$. The culture and mycelium were separated by centrifugation $\left(2500 x \mathrm{x}\right.$ at $4^{\circ} \mathrm{C}$ for 15 min). The culture medium (CF; $50 \mathrm{ml}$ ) was used to extract and purify GAs as described by Hamayun et al. [22,23]. Briefly, the $\mathrm{pH}$ of the CF was adjusted to 2.5 using $6 \mathrm{~N}$ $\mathrm{HCl}$ and was partitioned with ethyl acetate (EtOAc). Before partitioning, deuterated GAs internal standards (20 ng; [17, $\left.17-{ }^{2} \mathrm{H}_{2}\right] \mathrm{GA}_{1}, \mathrm{GA}_{3}, \mathrm{GA}_{4}, \mathrm{GA}_{8}, \mathrm{GA}_{12}$ and $\mathrm{GA}_{24}$ ) were added in the CF. Tritiated GAs i.e. $\left[1,2-{ }^{3} \mathrm{H}_{2}\right] \mathrm{GA}_{9}$ and $\left[1,2-{ }^{3} \mathrm{H}_{2}\right] \mathrm{GA}_{20}$ were also added (obtained from Prof. Lewis N. Mander, Australian National University, Canberra, Australia). The organic layer was vacuum dried and added with $60 \%$ methanol $(\mathrm{MeOH})$ while the $\mathrm{pH}$ was adjusted to $8.0 \pm 0.3$ using $2 \mathrm{~N} \mathrm{NH}_{4} \mathrm{OH}$. Similarly, endogenous GAs from cucumber plants treated with and without endophytic fungus and salinity stress were extracted from $0.5 \mathrm{~g}$ of freeze-dried plant samples according to the method of Lee et al. [31]. About $20 \mathrm{ng}$ each of deuterated $\left[17,17-{ }^{2} \mathrm{H}_{2}\right] \mathrm{GA}_{3}, \mathrm{GA}_{4}, \mathrm{GA}_{12}$ and $\mathrm{GA}_{20}$ internal standards were added. The CF and plant extracts were subjected to chromatographic and mass spectroscopy techniques for identification and quantification of GAs.

\section{Chromatography and GC/MS - SIM for hormonal analysis}

The extracts were passed through a Davisil C18 column (90-130 $\mu \mathrm{m}$; Alltech, Deerfield, IL, USA). The eluent was reduced to near dryness at $40^{\circ} \mathrm{C}$ in vacuum. The sample was then dried onto celite and then loaded onto $\mathrm{SiO}_{2}$ partitioning column (deactivated with $20 \%$ water) to separate the GAs as a group from more polar impurities. GAs were eluted with $80 \mathrm{ml}$ of 95: $5(\mathrm{v} / \mathrm{v})$ ethyl acetate (EtOAc): hexane saturated with formic acid. This solution was dried at $40^{\circ} \mathrm{C}$ in vacuum, re-dissolved in $4 \mathrm{ml}$ of EtOAc, and partitioned three times against $4 \mathrm{ml}$ of $0.1 \mathrm{M}$ phosphate buffer ( $\mathrm{pH}$ 8.0). Drop-wise addition of $2 \mathrm{~N} \mathrm{NaOH}$ was required during the first partitioning to neutralize residual formic acid. One-gram polyvinylpolypyrrolidone (PVPP) was added to the combined aqueous phases, and this mixture was slurried for $1 \mathrm{~h}$. The $\mathrm{pH}$ was reduced to 2.5 with $6 \mathrm{~N} \mathrm{HCl}$. The extract was partitioned three times against equal volumes of EtOAc. The combined EtOAc fraction was dried in vacuum, and the residue was dissolved in $3 \mathrm{ml}$ of $100 \% \mathrm{MeOH}$. This solution was dried on a Savant Automatic Environmental Speedvac (AES 2000, Madrid, Spain). The dried samples were subjected to high performance liquid chromatography (HPLC) using a $3.9 \times 300 \mathrm{~m}$ Bondapak C18 column (Waters Corp., Milford, MA, USA) and eluted at $1.0 \mathrm{ml} /$ min with the following gradient: 0 to $5 \mathrm{~min}$, isocratic $28 \%$ $\mathrm{MeOH}$ in $1 \%$ aqueous acetic acid; 5 to $35 \mathrm{~min}$, linear gradient from $28 \%$ to $86 \% \mathrm{MeOH}$; 35 to $36 \mathrm{~min}, 86 \%$ to $100 \% \mathrm{MeOH}$; 36 to $40 \mathrm{~min}$, isocratic 100\% MeOH. Fortyeight fractions of $1.0 \mathrm{ml}$ each were collected (Additional file 1). The fractions were then prepared for gas chromatography/mass spectrometry (GC/MS) with selected ion monitoring (SIM) system (6890N Network GC System, and 5973 Network Mass Selective Detector; Agilent Technologies, Palo Alto, CA, USA). For each GAs, $1 \mu$ of sample was injected in GC/MS SIM (Additional file 2). Full-scan mode (the first trial) and three major ions of the supplemented $\left[17-{ }^{2} \mathrm{H}_{2}\right]$ GAs internal standards and the fungal GAs were monitored simultaneously whereas the same was done for endogenous GAs of cucumber plants (Supplementary data 2). The fungal CF GAs $\left(\mathrm{GA}_{1}\right.$, $\mathrm{GA}_{3}, \mathrm{GA}_{4}, \mathrm{GA}_{8}, \mathrm{GA}_{9}, \mathrm{GA}_{12}, \mathrm{GA}_{20}$ and $\mathrm{GA}_{24}$ ) and the endogenous cucumber plant's GAs $\left(\mathrm{GA}_{3}, \mathrm{GA}_{4}\right.$ and $\left.\mathrm{GA}_{12}\right)$ were calculated from the peak area ratios of sample GAs to corresponding internal standards. The retention time was determined using hydrocarbon standards to calculate the KRI (Kovats retention index) value (Additional file 1). The limit of detection was determined for all GAs. GC/ MS SIM limit of detection was $20 \mathrm{pg} / \mathrm{ml}$ for fungal CF and plant samples. The data was calculated in nanograms per millilitre (for fungal CF) or nano-grams per grams fresh weight (for cucumber plants) while the analyses were repeated three times.

\section{IAA analysis}

Samples were analysed with a High Performance Liquid Chromatograph (HPLC) system, equipped with a differential ultraviolet (UV) detector absorbing at $280 \mathrm{~nm}$ and a C18 $(5 \mu \mathrm{m} ; 25 \times 0.46 \mathrm{~cm})$ column. Mobile phase was methanol and water $(80: 20[\mathrm{v} / \mathrm{v}])$ at a flow rate of $1.5 \mathrm{ml} /$ min. The sample injection volume was $10 \mu \mathrm{l}$. Retention times for the analyte peaks were compared to those of authentic internal standards added to the medium and 
extracted by the same procedures used with fungal cultures. Quantification was done by comparison of peak area [32].

\section{Endogenous ABA analysis}

The endogenous ABA was extracted according to the method of Qi et al. [33]. The extracts were dried and methylated by adding diazomethane. Analyses were done using a GC-MS SIM (6890N network GC system, and 5973 network mass selective detector; Agilent Technologies, Palo Alto, CA, USA). For quantification, the Lab-Base (ThermoQuset, Manchester, UK) data system software was used to monitor responses to ions of $\mathrm{m} / \mathrm{z} 162$ and 190 for Me-ABA and 166 and 194 for Me- $\left[{ }^{2} \mathrm{H}_{6}\right]-\mathrm{ABA}$ (supplementary data 2).

\section{Statistical analysis}

The analysis of variance and multiple mean comparisons were carried out on the data using Graph Pad Prism software (version 5.0, San Diego, California USA). The purpose of these tests was to identify statistically significant effects and interactions among various test and control treatments. The significant differences among the mean values of various treatments were determined using Duncan's multiple range tests (DMRT) at 95\% CI using Statistic Analysis System (SAS 9.1).

\section{Results}

\section{Effect of fungal CF on Waito-C and Dongjin-byeo rice} growth

We isolated 31 endophytic fungi from 120 roots of cucumber plants suggesting an abundance level of 3.87 endophytes per root sample. These fungi were grown on Hagem media plates for seven days. The pure culture plates were grouped on the basis of colony shape, height and colour of aerial hyphae, base colour, growth rate, margin characteristics, surface texture and depth of growth into medium [34]. The morphological trait analysis reveals that only nine endophytes were different. The CF of these nine different endophytes were assayed on Waito- $C$ and Dongjin-byeo rice seedlings to differentiate between growth stimulatory or inhibitory and plant hormones producing strains. The growth attributes of dwarf Waito-C (GAs mutant dwarf cultivar) and Dongjin-byeo (normal GAs cultivar) rice seedlings were recorded after a week of treatment and the data is given in Table 1 and Table 2. The results showed that $\mathrm{CF}$ application of $\mathrm{CSH}-6 \mathrm{H}$ to Waito-C and Dongjin-byeo rice seedlings exhibit significant growth promotion as compared to the CF of G. fujikuroi and DDW applied control rice seedlings. Endophyte, CSH-6H significantly increased the shoot growth of dwarf Waito-C rice in comparison controls. The $\mathrm{CSH}-6 \mathrm{H}$ applied CF exhibited higher chlorophyll content and shoot fresh weight of rice seedlings than controls (Table 1). A similar growth stimulatory trend of $\mathrm{CSH}-6 \mathrm{H}$ was observed on the Dongjin-byeo rice seedling with active GAs biosynthesis pathway and normal phenotype (Table 2). In other growth promoting strain, $\mathrm{CSH}-7 \mathrm{C}$ and $\mathrm{CSH}-7 \mathrm{~B}$ improved the shoot growth, fresh weight and chlorophyll content of Waito-C and Dongjin-byeo rice seedlings but it was not significantly different than the CF of G. fujikuroi (Table 1 and Table 2). In growth suppressive strains, CSH-1A inhibited the growth of Waito-C and Dongjinbyeo as compared other endophytic fungal strains. Upon significant growth promoting results of $\mathrm{CSH}-6 \mathrm{H}$, it was selected for identification and further investigation.

\section{Identification and phylogenetic analysis of bioactive endophyte}

After DNA extraction and PCR analysis of ITS regions, phylogenetic analysis of $\mathrm{CSH}-6 \mathrm{H}$ was carried out $[14,22,23]$. Maximum parsimony (MP) consensus tree was constructed from 16 (15 references and 1 clone) aligned partial ITS regions sequences with $1 \mathrm{~K}$ bootstrap replications. Selected strains were run through BLAST search. Results of BLAST search revealed that fungal strain CSH$6 \mathrm{H}$ has $100 \%$ sequence similarity with Paecilomyces $s p$. In MP dendrogram CSH-6H formed 86\% bootstrap support with Paecilomyces formosus (Figure 1). The sequence was submitted to NCBI GenBank and was given accession no. HQ444388. On the basis of sequence similarity and phylogenetic analysis results, $\mathrm{CSH}-6 \mathrm{H}$ was identified as a strain of $P$. formosus LHL10.

\section{Bioactive endophytic fungal CF analysis for phytohormones}

The CF of bioactive $P$. formosus $(\mathrm{CSH}-6 \mathrm{H})$ was analysed for its potential to produce GAs in the growing medium. We detected 8 different physiologically active and nonactive gibberellins (Figure 2) using GC/MS selected ion monitor. Among biologically active GAs, $\mathrm{GA}_{1}(1.3 \mathrm{ng} / \mathrm{ml})$, $\mathrm{GA}_{3}(1.1 \mathrm{ng} / \mathrm{ml})$ and $\mathrm{GA}_{4}(18.2 \mathrm{ng} / \mathrm{ml})$ were found in the various HPLC fractions (Additional file 1). Among physiologically in-active GAs, $\mathrm{GA}_{8}(37.2 \mathrm{ng} / \mathrm{ml}), \mathrm{GA}_{9}(5.5 \mathrm{ng} / \mathrm{ml})$, $\mathrm{GA}_{12}(1.4 \mathrm{ng} / \mathrm{ml}), \mathrm{GA}_{20}(2.2 \mathrm{ng} / \mathrm{ml})$ and $\mathrm{GA}_{24}(13.6 \mathrm{ng} / \mathrm{ml})$ were present in the CF. The quantities of bioactive $\mathrm{GA}_{4}$ and $\mathrm{GA}_{8}$ were significantly higher than the other GAs. Besides GAs, we also found IAA in the growing culture medium of $P$. formosus. The quantity of IAA was $10.2 \pm$ $1.21 \mu \mathrm{g} / \mathrm{ml}$

\section{Effect of $P$. formosus association on cucumber growth in salinity stress}

To assess the role of $P$. formosus in cucumber plant growth under saline soil condition, the endophyte was inoculated to the host plants. After three weeks of endophyte and host-plant association, $\mathrm{NaCl}$ was applied to induce salinity stress. The results reveal that the phytohormone producing 
Table 1 Effect of CF of endophytic fungal strains isolated from the roots of field grown cucumber plants on the growth of Waito-C rice seedlings

\begin{tabular}{|c|c|c|c|}
\hline Isolates & Shoot length $(\mathrm{cm})$ & Fresh weight (g) & Chlorophyll contents (SPAD) \\
\hline Control (Gf) & $8.0 \pm 0.18 b$ & $0.6 \pm 0.03 b$ & $31.5 \pm 0.39 b$ \\
\hline Control (DW) & $6.1 \pm 0.11 d$ & $0.5 \pm 0.06 c$ & $29.9 \pm 0.16 c$ \\
\hline $\mathrm{CSH}-1 \mathrm{~A}$ & $6.6 \pm 0.11 d$ & $0.2 \pm 0.05 e$ & $30.1 \pm 0.24 c$ \\
\hline $\mathrm{CSH}-3 \mathrm{C}$ & $7.2 \pm 0.12 c$ & $0.3 \pm 0.05 d$ & $31.1 \pm 1.43 b$ \\
\hline $\mathrm{CSH}-6 \mathrm{H}$ & $9.8 \pm 0.19 a$ & $0.9 \pm 0.05 a$ & $32.9 \pm 0.13 a$ \\
\hline CSH-6D & $7.3 \pm 0.13 c$ & $0.4 \pm 0.01 d$ & $29.3 \pm 0.23 c$ \\
\hline $\mathrm{CSH}-7 \mathrm{C}$ & $8.7 \pm 0.12 b$ & $0.7 \pm 0.03 b$ & $31.6 \pm 0.31 b$ \\
\hline $\mathrm{CSH}-5 \mathrm{C}$ & $8.4 \pm 0.12 b$ & $0.5 \pm 0.05 c$ & $31 \pm 1.52 b$ \\
\hline $\mathrm{CSH}-7 \mathrm{~B}$ & $8.5 \pm 0.16 b$ & $0.6 \pm 0.07 b$ & $24.3 \pm 1.22 \mathrm{~d}$ \\
\hline CSH-5D & $8.3 \pm 0.20 b$ & $0.6 \pm 0.07 b$ & $31 \pm 0.54 b$ \\
\hline CSH-8D & $8.4 \pm 0.13 b$ & $0.4 \pm 0.02 d$ & $29.6 \pm 0.77 c$ \\
\hline
\end{tabular}

Control (Gf) = rice seedlings treated with the CF of a wild-type strain of Gibberella fujikuroi KCCM12329; Control (DW) = rice seedlings treated with autoclaved distilled water. SPAD = Soil plant analysis development. In each column, treatment means having different letter are significantly $(P<0.05)$ different as evaluated by DMRT. Values in the table refer to mean \pm SD $(n=18)$

$P$. formosus significantly increased the host-plant growth under normal growth conditions. The endophyte symbiosis increased the shoot length up to $6.89 \%$ as compared to non-inoculated control plants (Figure 3). Upon salinity stress of $60 \mathrm{mM}$, the plants inoculated with $P$. formosus had $4.5 \%$ higher shoot growth as compared to non-inoculated control. When exposed to $120 \mathrm{mM} \mathrm{NaCl}$, endophyteinoculated plants had $15.9 \%$ higher shoot length than control plants. P. formosus inoculated enhanced the chlorophyll content, shoot fresh and dry weights, photosynthesis rate, stomatal conductance and transpirational rate both under salinity stress in comparison to the non-inoculated control plants (Table 3). The light microscopic analysis also showed the active association and habitation of $P$. formosus inside the plant's root (Figure 4abc). Fungal hypha (brownish) has been observed in the cucumber plant roots (Figure 4a). The hypha from the epidermal region into cortex cells forms a dense network at the end in the cortex cells. The P. formosus was also observed in the endodermal cells occupying the pericycle region (Figure $4 \mathrm{~b}$ ). In the periclycle region, hyphae underwent further morphological changes, switching to yeast-like cells or conidia (Figure 4c). The fungus was re-isolated successfully from salinity stressed plants and was again identified through sequencing the ITS regions and phylogenetic analysis as mentioned earlier. Thus, confirming that P. formosus is responsible for establishing ameliorative interaction with host plants during stress conditions.

\section{Plant water potential and stress mitigation}

Relative water potential was not significantly different in $P$. formosus inoculated plants and non-inoculated plants. Under salinity stress (60 and $120 \mathrm{mM}$ ), the endophyteinoculated cucumber plants showed significantly higher water potential as compared to the non-inoculated control plants (Figure 5a). The higher RWC indicates the beneficial endophytic association and rescuing role of $P$. formosus to curtail the adverse effects salinity stress.

Table 2 Effect of CF of endophytic fungal strains on the growth of Oryza sativa L. cv. Dongjin-beyo rice seedlings

\begin{tabular}{|c|c|c|c|}
\hline Isolates & Shoot length $(\mathrm{cm})$ & Fresh weight (g) & Chlorophyll contents (SPAD) \\
\hline Control (Gf) & $13.4 \pm 0.41 b$ & $0.8 \pm 0.04 b$ & $29.5 \pm 0.40 \mathrm{~b}$ \\
\hline Control (DW) & $10.0 \pm 0.42 d$ & $0.6 \pm 0.06 c$ & $20.0 \pm 0.62 d$ \\
\hline $\mathrm{CSH}-1 \mathrm{~A}$ & $8.7 \pm 1.44 \mathrm{e}$ & $0.5 \pm 0.05 d$ & $24.3 \pm 1.21 \mathrm{C}$ \\
\hline $\mathrm{CSH}-3 \mathrm{C}$ & $11.3 \pm 0.91 c$ & $0.6 \pm 0.05 c$ & $20.0 \pm 0.92 d$ \\
\hline $\mathrm{CSH}-6 \mathrm{H}$ & $15.6 \pm 0.27 a$ & $1.1 \pm 0.05 a$ & $31.8 \pm 0.21 a$ \\
\hline CSH-6D & $10.6 \pm 0.92 c$ & $0.4 \pm 0.01 d$ & $29.3 \pm 0.68 b$ \\
\hline $\mathrm{CSH}-7 \mathrm{C}$ & $13.9 \pm 1.0 \mathrm{~b}$ & $0.8 \pm 0.08 b$ & $14.8 \pm 0.71 e$ \\
\hline $\mathrm{CSH}-5 \mathrm{C}$ & $10.0 \pm 0.44 d$ & $0.5 \pm 0.05 d$ & $15.3 \pm 0.93 e$ \\
\hline $\mathrm{CSH}-7 \mathrm{~B}$ & $14.8 \pm 0.57 b$ & $0.8 \pm 0.07 b$ & $16.9 \pm 2.71 \mathrm{e}$ \\
\hline $\mathrm{CSH}-5 \mathrm{D}$ & $13.3 \pm 0.75 b$ & $0.9 \pm 0.07 b$ & $23.0 \pm 0.54 c$ \\
\hline $\mathrm{CSH}-8 \mathrm{D}$ & $13.2 \pm 0.41 b$ & $0.8 \pm 0.02 b$ & $29.6 \pm 0.73 b$ \\
\hline
\end{tabular}

Control (Gf) = rice seedlings treated with the CF of a wild-type strain of Gibberella fujikuroi KCCM12329; Control (DW) = rice seedlings treated with autoclaved distilled water; SPAD = Soil plant analysis development. In each column, treatment means having different letter(s) are significantly $(P<0.05)$ different as determined by DMRT. Values in the table refer to mean \pm SD $(n=18)$. 


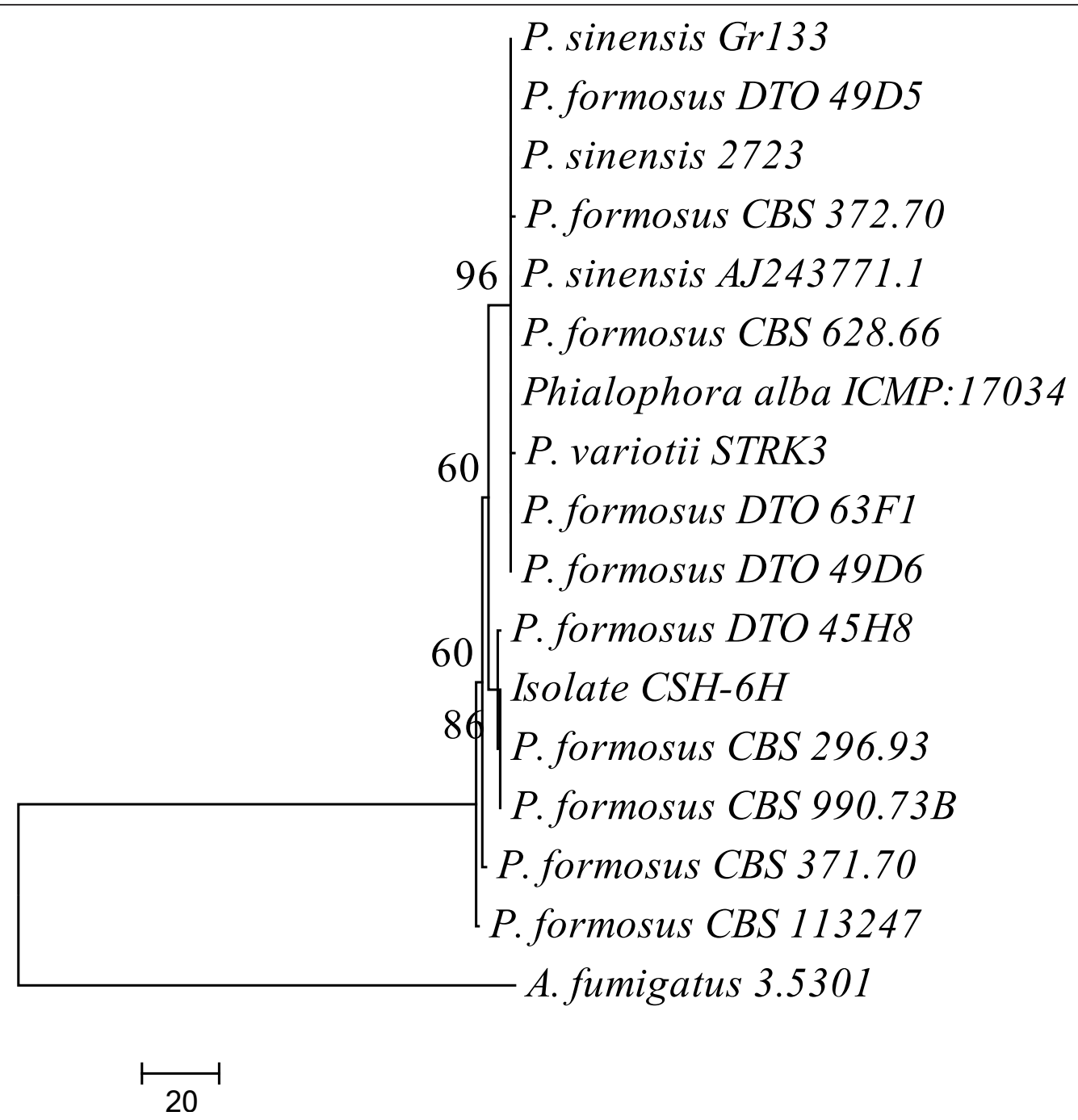

Figure 1 Phylogenetic tree constructed through maximum parsimony method using MEGA 4.0 (Tamura et al. 2007). The sequence obtained from ITS regions of rDNA of Paecilomyces formosus LHL10 and related fungi. The bioactive endophytic fungal strain formed a sub-clade (86\% bootstrap support) with Paecilomyces sp. Aspergillus fumigatus was taken as an out-group.

The electrolytic leakage (EL) from the cellular apparatus was almost similar in both endophyte associated plants and endophyte-free plants. However, upon salinity stress (60 and $120 \mathrm{mM}$ ), the non-inoculated control plants released significantly higher electrolytes as compared to $P$. formosus associated plants (Figure $5 \mathrm{~b}$ ). It suggests that the endophyte interaction counteracted the adverse effect of salinity by reducing the damage to the cellular membranes of the plants. The mitigating response of $P$. formosus association in salinity stress was further assessed the extent of lipid peroxidation. The results showed that MDA content was significantly lower in endophyte associated plants than control without $\mathrm{NaCl}$ stress. Upon salinity stress (60 and $120 \mathrm{mM}$ ), we again observed the significantly reduced levels of lipid peroxidation product
(MDA) in the endophyte-inoculated plants than the control plants (Figure 5c).

The results showed that free proline quantity was not significantly different in cucumber plants inoculated with $P$. formosus and control. Treating cucumber plants with $60 \mathrm{mM} \mathrm{NaCl}$ stress, $P$. formosus inoculated plants had higher proline quantity in comparison to control. Cucumber plants when treated with 60 or $120 \mathrm{mM}$ $\mathrm{NaCl}$ stress, $P$. formosus inoculated plants had higher proline quantity in comparison to controls (Figure 5d). To maintain the a high capacity of nitrogen for plant growth during salinity stress, we observed significantly higher assimilation of nitrogen endophyte-associated plant than endophyte free control plants with (60 and $120 \mathrm{mM}$ ) or without salinity stress (Figure 5e). Besides 


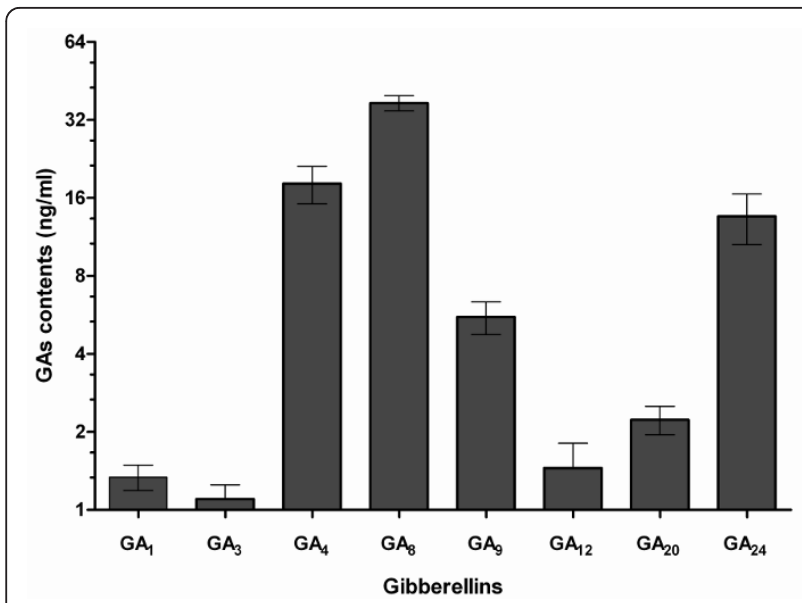

Figure 2 Quantities of various GAs found in the CF of $P$. formosus The experiment was repeated three times using already established method of Lee et al. (1998) through GC/MS-SIM. Each value is the mean \pm SE of three replicates.

that, $P$. formosus inoculated plants exhibited higher oxidant radical scavenging by producing higher antioxidants as compared to control plants. After 60 and 120 $\mathrm{mM} \mathrm{NaCl}$ application, the level of antioxidant production was significantly higher in $P$. formosus treated plants in comparison to non-inoculated control plants (Figure 5f).

\section{Effect of $P$. formosus on endogenous $\mathrm{ABA}$ and GAs under} stress

Our results showed that the stress responsive endogenous ABA content in fungi inoculated plants was not significantly different than control plants. Upon $\mathrm{NaCl}$ stress treatments $(60$ and $120 \mathrm{mM})$ the cucumber plants

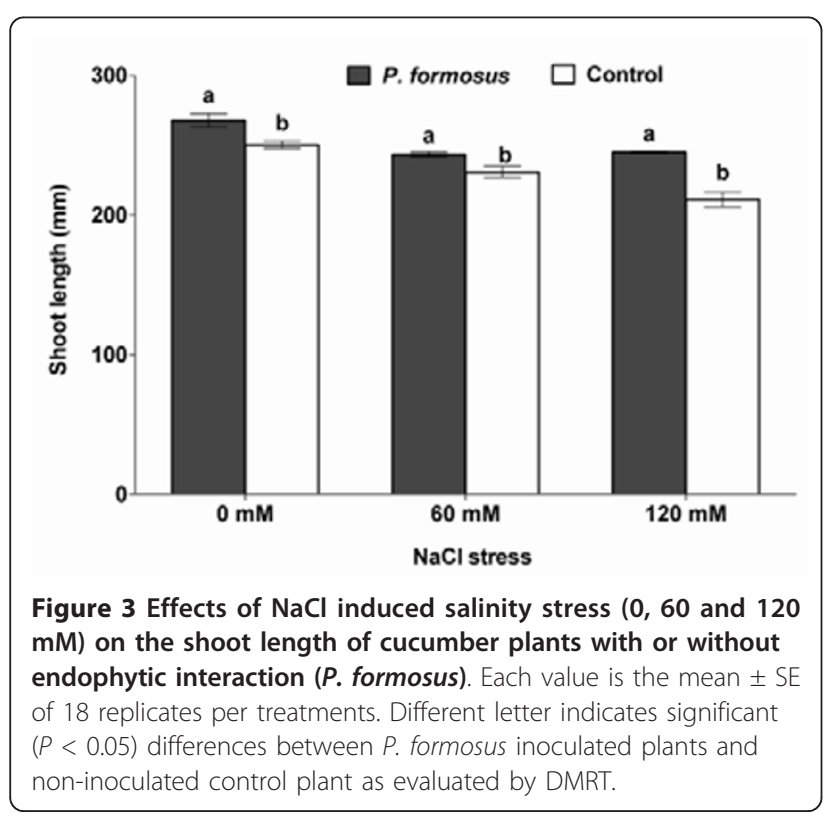

with $P$. formosus association had significantly lower level of ABA content as compared to control plants (Figure 6). In case of endogenous GAs content, we analyzed the $\mathrm{GA}_{12}, \mathrm{GA}_{20}, \mathrm{GA}_{4}$ and $\mathrm{GA}_{3}$ of cucumber plants treated with or without salinity stress and $P$. formosus. We found that $\mathrm{GA}_{12}$ synthesis is almost same in both endophyte-associated and control plants under normal growth conditions. However, upon salinity stress (60 and $120 \mathrm{mM}$ ), the $\mathrm{GA}_{12}$ was significantly increased in endophyte-associated plants than the endophyte-free control plants (Figure 7). Similarly, $\mathrm{GA}_{20}$ was not significantly different in endophyte inoculated plants and control plants. After $\mathrm{NaCl}$ treatments $(60$ and $120 \mathrm{mM})$, the $\mathrm{GA}_{20}$ synthesis by cucumber plants inoculated with endophyte was significantly higher as compared to control plants (Figure 7). The $\mathrm{GA}_{4}$ content was significantly up-regulated in P. formosus associated plants than the control plants under normal and salinity stress $(60$ and $120 \mathrm{mM}$ ) conditions. A similar trend was also observed for $\mathrm{GA}_{3}$ contents (Figure 7).

\section{Discussion}

We used screening bioassays and hormonal analysis of endophytic fungal CF in order to identify bioactive fungal strains, because fungi has been an exploratory source of a wide range of bioactive secondary metabolites $[8,25]$. In screening bioassays, rice cultivars were used as rice can easily grow under controlled and sterilized conditions using autoclaved water-agar media. Waito-C and Dongjin-byeo rice seedlings grown in hydroponic medium can help in assessment of CF obtained from endophytic fungi [14]. Waito- $C$ is a dwarf rice cultivar with mutated $d y$ gene that controls the $3 \beta$-hydroxylation of $\mathrm{GA}_{20}$ to $\mathrm{GA}_{1}$. The Waito- $C$ seeds were also treated with GAs biosynthesis inhibitor (uniconazol) to further suppress the GAs biosynthesis mechanism [35]. Dongjin-byeo, on the other hand, has normal phenotype with active GAs biosynthesis pathway [35]. Since Waito-C and Dongjin-byeo growth media were devoid of nutrients, therefore, the sole effect of $\mathrm{CF}$ on rice was easily determined. Current study confirmed earlier reports stating that rice shoot growth stimulation or suppression can be attributed to the activity of plant growth promoting or inhibiting secondary metabolites present in the fungal CF $[22,23]$. The effect of CF from P. formosus was similar to that of $G$. fujikuroi, which possess an active GAs biosynthesis pathway [18]. Waito-C and Dongjin-byeo growth promotion triggered by the CF of $P$. formosus was later rectified as it contained physiologically active GAs and IAA. Upon significant growth promotive results in comparison to other fungal isolates, $P$. formosus was selected for identification and further investigation.

The endophytes releasing plant growth hormones, in present case, GAs and IAA can enhance plant growth. 
Table 3 Effect of salt stress on the growth of cucumber plants with or without endophyte inoculation

\begin{tabular}{|c|c|c|c|c|c|c|}
\hline \multirow[t]{2}{*}{ Growth attributes/salt stress } & \multicolumn{2}{|c|}{$0 \mathrm{mM}$} & \multicolumn{2}{|c|}{$60 \mathrm{mM}$} & \multicolumn{2}{|c|}{$120 \mathrm{mM}$} \\
\hline & Control & P. formosus & Control & P. formosus & Control & P. formosus \\
\hline Chlorophyll content (SPAD) & $27.3 \pm 0.18 b$ & $29.1 \pm 0.12 \mathrm{a}$ & $28.0 \pm 0.24 b$ & $36.5 \pm 0.25 a$ & $24.3 \pm 0.26 b$ & $37.1 \pm 0.14 a$ \\
\hline Shoot fresh weight (g) & $14.9 \pm 0.33 b$ & $17.4 \pm 0.15 a$ & $16.3 \pm 0.29 b$ & $17.3 \pm 0.16 \mathrm{a}$ & $13.4 \pm 0.35 b$ & $15.0 \pm 0.41 a$ \\
\hline Shoot dry weight (g) & $2.7 \pm 0.07 b$ & $3.1 \pm 0.08 \mathrm{a}$ & $1.3 \pm 0.01 b$ & $1.7 \pm 0.02 \mathrm{a}$ & $1.1 \pm 0.01 b$ & $1.5 \pm 0.09 a$ \\
\hline Leaf area $\left(\mathrm{cm}^{2}\right)$ & $58.6 \pm 0.61 b$ & $62.1 \pm 0.43 a$ & $48.9 \pm 0.42 b$ & $52.4 \pm 0.66 a$ & $40.9 \pm 0.67 b$ & $43.1 \pm 0.12 \mathrm{a}$ \\
\hline Photosynthesis rate $\left(\mu \mathrm{molm}^{-2} \mathrm{~s}^{-1}\right)$ & $1.4 \pm 0.05 b$ & $1.7 \pm 0.02 a$ & $1.1 \pm 0.03 b$ & $1.5 \pm 0.04 a$ & $1.0 \pm 0.06 b$ & $1.2 \pm 0.03 a$ \\
\hline Stomatal conductance $\left(\mathrm{molm}^{-2} \mathrm{~s}^{-1}\right)$ & $1.5 \pm 0.02 b$ & $2.9 \pm 0.01 a$ & $1.7 \pm 0.06 b$ & $2.0 \pm 0.03 a$ & $2.1 \pm 0.02 b$ & $2.5 \pm 0.08 \mathrm{a}$ \\
\hline Transpiration rate $\left(\mathrm{mMm}^{-2} \mathrm{~s}^{-1}\right)$ & $0.07 \pm 0.01 b$ & $0.12 \pm 0.01 a$ & $0.06 \pm 0.01 b$ & $0.16 \pm 0.01 a$ & $0.02 \pm 0.01 b$ & $0.18 \pm 0.01 a$ \\
\hline
\end{tabular}

$0 \mathrm{mM}$ means only distilled water applied plants while 60 and $120 \mathrm{mM}$ is the $\mathrm{NaCl}$ concentrations applied to the cucumber plants. SPAD = Soil plant analysis development. In each row, different letter indicates significant $(P<0.05)$ differences between $P$. formosus inoculated plants with non-inoculated control plant as evaluated by DMRT. Values in the table refer to mean \pm SD $(n=18)$.

In current study, detection of GAs in the growing medium of $P$. formosus suggests that during interaction GAs were secreted causing growth promotion and also conferred ameliorative capacity to cucumber plants under salinity stress. Previous reports also confirm that fungal endophytes produce phytohormones. For instance, Hassan [24] reported that Aspergillus flavus, A. niger, Fusarium oxysporum, Penicillium corylophilum, P. cyclopium, P. funiculosum and Rhizopus stolonifer have the capacity to produce GAs, while $F$. oxysporum can secrete both GAs and IAA. Similarly, Khan et al. [16] reported that P. funiculosum can produce bioactive GAs and IAA. Phaeosphaeria sp. L487 was also found to possess GAs biosynthesis apparatus and can produce $\mathrm{GA}_{1}$ [21]. The CF of our fungal isolate also contained IAA, which is a molecule synthesized by plants and a few microbes [32], and has been known for its active role in plant growth regulation [36], while its biosynthesis pathway has been elucidated in bacterial strain [37]. The presence of IAA in P. formosus clearly suggests the existence of IAA biosynthesis pathway as reported for some other classes of fungi by Tuomi et al. [38]. Plants treated with endophytes are often healthier than those lacking such interaction [7-14], which may be attributed to the endophyte secretion of phytohormones such as IAA [16,36] and GAs [14-16,18,21-24]. In endophyte-host symbioses, secondary metabolites may be a contribution of the endophytic partner for such mutualistic relationship [9].

Endophytic fungi residing in root tissues and secreting plant growth regulating compounds are of great interest to enhance crop yield and quality. Such growth regulating compounds can influence plant development as well as rescue plant growth in stressful environments. Like many other plants, cucumber is more susceptible to salt stress $[39,40]$. Current study showed that $P$. formosus inoculation significantly improved plant growth and alleviated salinity induced stress. The presence of IAA and GAs in the CF of the fungus further rectifies our results, as both of them promote plant growth and development [41]. The presence of $P$. formosus in the cortical cells and their successful re-isolation by us further strengthens the active role of $P$. formosus in the host cucumber plants. The mutualistic relations of $P$. formosus with cucumber plant may have helped the host plant to mitigate the adverse effects of salinity stress. Similarly, recently Redman et al. [42] reported that IAA producing endophytic fungi can enhance rice plant growth under salinity, drought and temperature stress. Previously, Khan et al. $[15,16]$ confirmed that GAs producing endophytic fungal strains ( $P$. funiculosum and Aspergillus fumigatus) can ameliorate soybean plant growth under moderate and high salinity stress. Hamayun et al. $[22,23]$ also reported that GAs secreting fungal endophytes promote soybean growth components. Many other studies also reported similar findings narrating that fungal interaction can enhance plants growth under stress conditions $[9,12,43,44]$.

Plant growth and development depend upon leaf water contents, as salt stress trigger water deficit inside the plant tissues [4], and measurement of RWC helps to indicate stress responses of plant and relative cellular volumes [27]. Our current findings confirm earlier studies $[43,44]$, suggesting that the fungal inoculated plants not only avoid stress but also help the plant to fetch higher water contents from sources usually inaccessible to control plants. Abiotic stresses cause higher electrolyte discharge (like $\mathrm{K}^{+}$ions) through displacement of membrane-associated Ca from plasma lemma. Resultantly, cellular membrane stability is damaged and aggregating higher efflux of electrolytes inside the plant tissues [27]. Our findings showed that plants associated with $P$. formosus had lower electrolytic leakage than control plants under salt stress. This indicated a lower permeability of plasma membrane attributed to the integrity and stability of cellular tissues due to endophyte-plant interaction as compared to control treatments [45]. On the other hand, antioxidant scavengers can enhance membrane thermostability against ROS attack, while MDA content can be used to assess injuries to plants [45]. It has been shown that peroxides of 

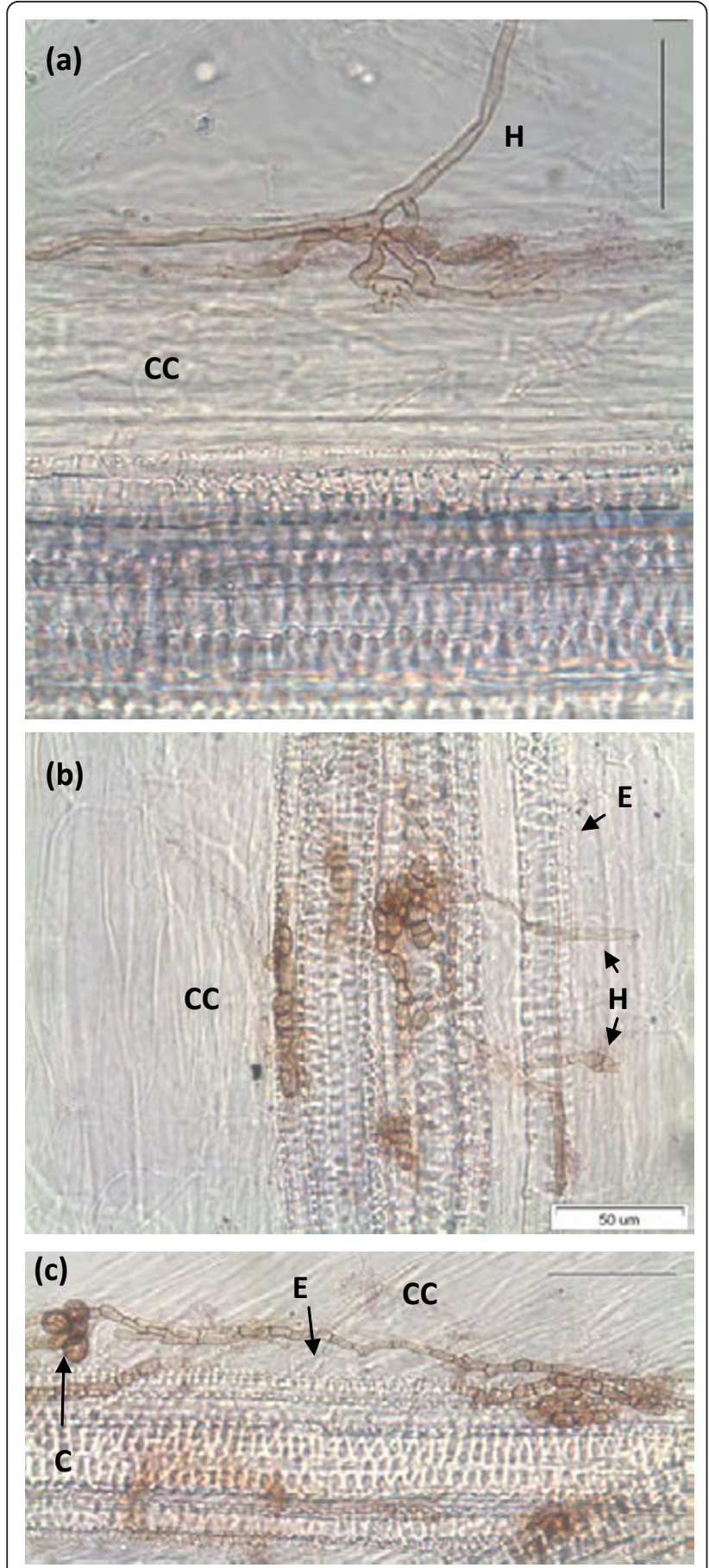

Figure 4 Light microscopic analysis of cucumber root colonized by $P$. formosus. The fungus was observed: (a) forming hypha from epidermal region into cortical region; (b) developing in endodermal cells (c) switching to yeast-like cells or conidia in the periclycle region by undergoing morphological changes. $\mathrm{H}=$

Hypha; CC = cortex cells; $\mathrm{E}=$ endodermal cells; $\mathrm{C}=$ conidia or yeast like cells; scale bar $50 \mu \mathrm{m}$. polyunsaturated fatty acids generate MDA on decomposition, and in many cases MDA is the most abundant individual aldehydic lipid breakdown product [30]. The higher MDA level is perceived with higher ROS production and cellular membrane damage. In our study, low levels of lipid peroxidation in $P$. formosus treated plants showed reduced cellular damage to cucumber plants growing under salinity stress as compared to control. Similarly, in saline conditions, osmo-protectants like proline accumulate to provide an energy source for plant growth and survival by preventing ionic and osmotic imbalances [46]. We observed significant aggregation of proline in P. formosus associated plants growing under salinity stress, suggesting a decline in ionic influx inside the cellular masses and rescuing cucumber plants to maintain its osmotic balance. Similarly, higher nitrogen uptake by endophyte-inoculated plants under salinity suggested the regulation of sodium ion toxicity to indirectly maintain chlorophyll and osmotic balance [47]. Sodium and chloride ion toxicity can trigger the formation of ROS which can damage cellular functioning [45-48]. Resultantly, accumulation of antioxidants inside plant can extend greater resistance to oxidative damage [48]. Higher DPPH radical scavenging activity in $P$. formosus inoculated plants suggest greater oxidative stress regulation than non-inoculated plants [4]. Several studies have suggested that fungal symbiosis helps plants to mitigate stress by increasing antioxidant activities $[29,46,48]$.

Under salinity stress, phytohormones like ABA can protect plants by stomatal closure to minimize water loss and then mediates stress damage [49]. It is widely described that $\mathrm{ABA}$ contents in plants increase under salt stress $[1,50]$. However, our finding shows significantly lower ABA level in endophyte-associated plants as compared to endophyte-free plants. Previously, Jahromi et al. [51] observed the same findings after association of Glomus intraradices with lettuce plants. Similarly, when soybean were given salinity stress in the presence of phytohormones producing endophytic fungi (Penicillium funiculosum and Aspergillus fumigatus), ABA levels were declined $[15,16]$, whilst the plants experienced lesser amount of stress. Since ABA is involved in the regulation of stress signalling during plant growth therefore, its biosynthesis can be affected by the presence of fungal interaction in abiotic stress. Although other studies suggests that fungal inoculation have increased the ABA content in leaves and roots compared with non-inoculation control plants [52]. However, the effect may fluctuate among difference class of microorganisms and plant species as some 
(a)
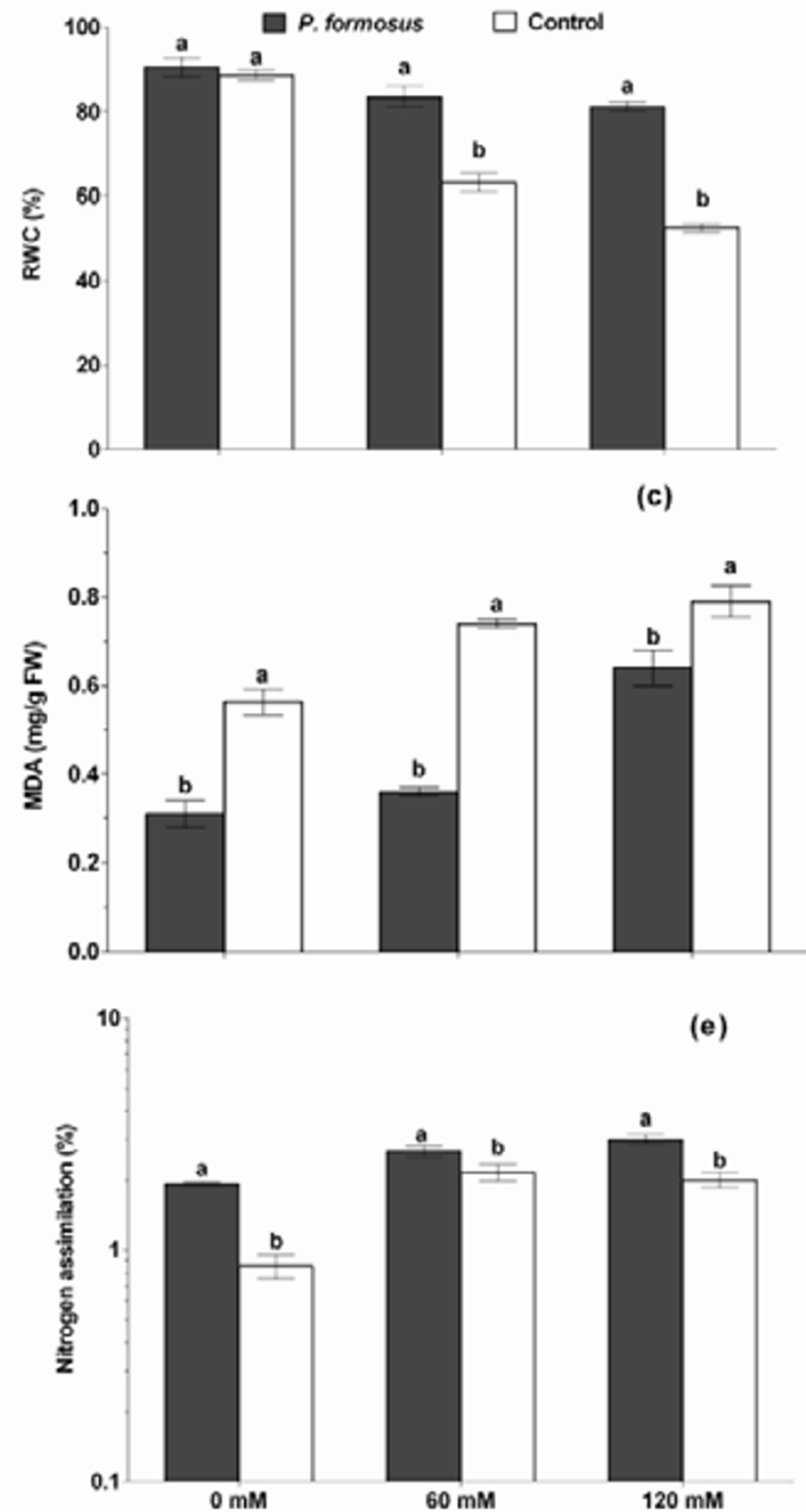

(b)

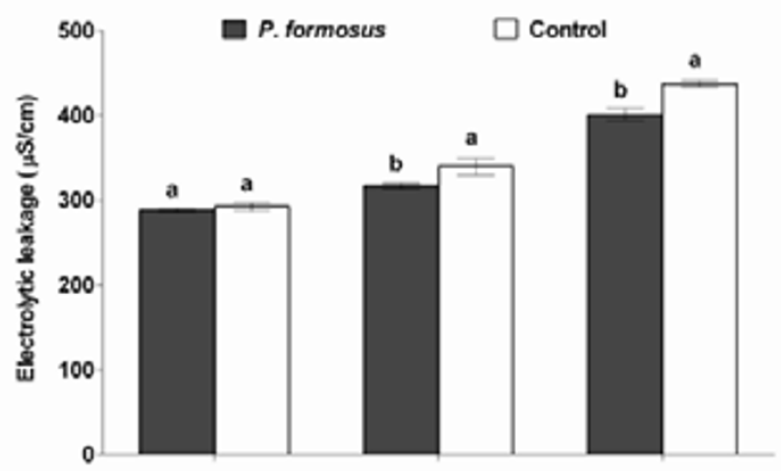

(d)

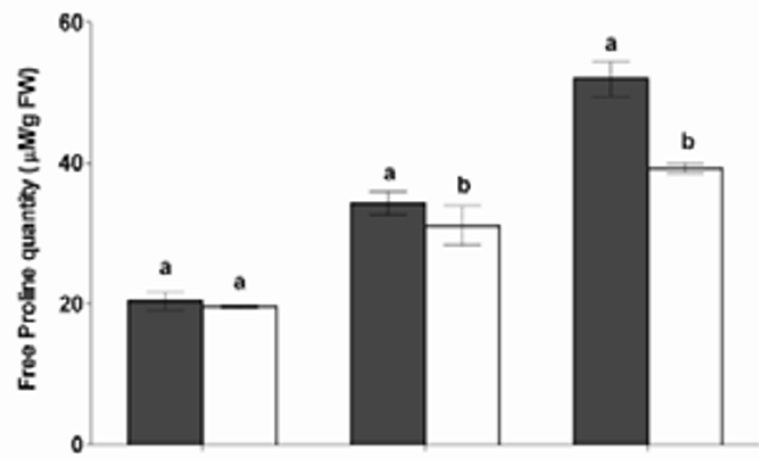

(f)

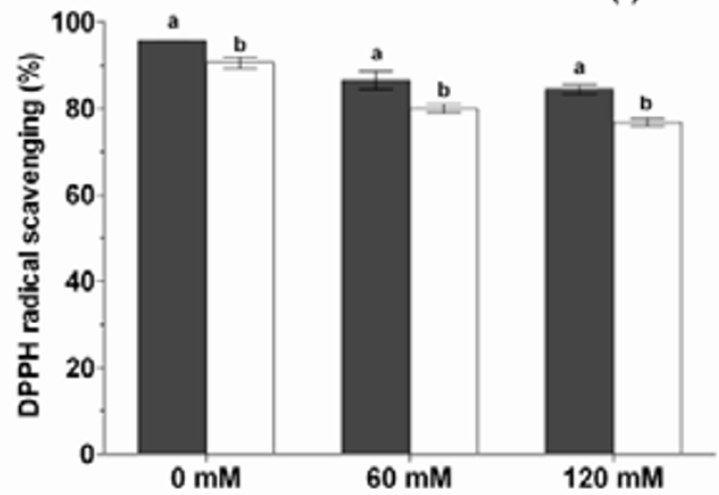

Figure 5 Effects of the $\mathrm{NaCl}$ stress $(0,60$ and $120 \mathrm{mM}$ ) on the relative water contents (a), electrolytic leakage (b), MDA content (c), free proline quantity (d), nitrogen assimilation (e), and antioxidant activity (f) of cucumber plants with or without endophytic inoculation $(\boldsymbol{P}$. formosus). Each value is the mean \pm SE of 3 replicates per treatments. Different letter indicates significant $(P<0.05)$ differences between $P$. formosus inoculated plants and non-inoculated control plant as evaluated by DMRT.

earlier reports have elaborated this [44,53]. There are several studied which narrates the same findings of low ABA levels under stress and fungal association [44]. Exogenous application of $\mathrm{GA}_{3}$ improved soybean salinity stress tolerance by increasing plant biomass while accumulating lesser ABA [54]. Iqbal and Ashraf [55] observed that $\mathrm{GA}_{3}$ application can results in altered level of ABA under salinity stress in Triticum aestivum L. Although, higher ABA in salinity is correlated with inhibition of leaf expansion and shoots development in different species [56] however, P. formosus inoculated plants counteracted adverse effects of stress by significantly increasing leaf area and shoot length as compared to control plants. Similarly, in case of cucumber plant's 


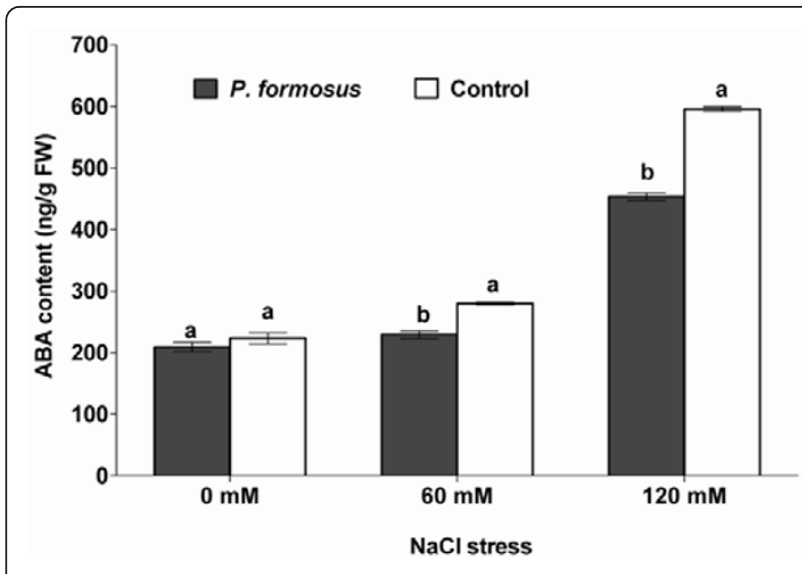

Figure 6 Effect of $\mathrm{NaCl}$ induced salt stress on endogenous $\mathrm{ABA}$ content of the cucumber plants in the presence of $P$. formosus inoculation. Each value is the mean \pm SE of 3 replicates per treatments. Different letter indicates significant $(P<0.05)$ differences between $P$. formosus inoculated plants and non-inoculated control plant as evaluated by DMRT. endogenous GAs, endophytic fungal application have rescued GAs biosynthesis as the level of bioactive GAs were much pronounced compared to sole $\mathrm{NaCl}$ treated plants. Phytohormones, like GAs have been widely known for their role in plant growth and various developmental processes during plant's life cycle $[1,3,57]$. Normal response of a plant to stress is to reduce growth by inter alia increasing $\mathrm{ABA}$ content and reducing GAs $[56,57]$. GA-deficient plants are more susceptible to stress than those with higher levels of this hormone [56]. The higher amount of $\mathrm{GA}_{12}$ in endophyte-treated plant under salinity stress elucidates the activation of GAs biosynthesis pathway, while higher production of $\mathrm{GA}_{3}$ and $\mathrm{GA}_{4}$ confirm plant growth maintenance during stress condition. Thus, by maintaining GAs and, therefore, growth under stressful conditions, the endophyte is having a detrimental effect on the plant long-term survival. There are many previous reports showing the ameliorative effects of exogenous application of GAs $\left(\mathrm{GA}_{3} /\right.$ $\mathrm{GA}_{4}$ ) and IAA on cucumber growth under abiotic stress [58-60], while very little or no information's are available
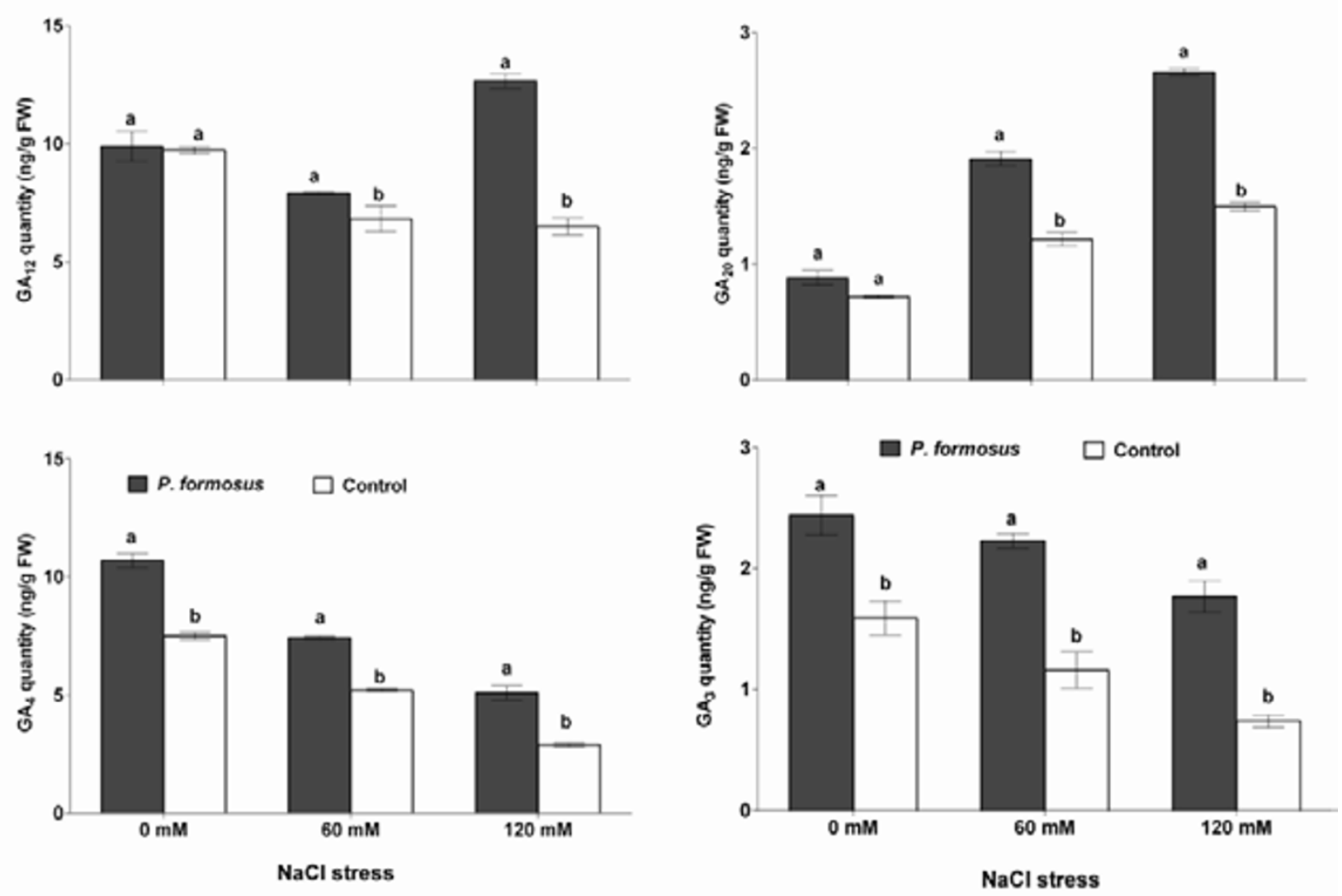

Figure 7 Influence of salinity stress on the $\mathrm{GAs}\left(\mathrm{GA}_{3}, \mathrm{GA}_{4} \mathrm{GA}_{12}\right.$ and $\left.\mathrm{GA}_{20}\right)$ contents of the plant's leaves with or without $P$. formosus inoculation. Each value is the mean \pm SE of 3 replicates per treatments. Different letter indicates significant $(P<0.05)$ differences between $P$. formosus inoculated plants and non-inoculated control plant as evaluated by DMRT. 
on the regulation of plant endogenous hormones in association with phytohormones producing endophytic fungi under abiotic stress conditions. Some physiological evidence suggests that plants infected with endophytic fungi often have a distinct advantage against biotic and abiotic stress over their endophyte-free counterparts [61]. Beneficial features have been offered in infected plants; including drought acclimisation $[62,63]$ enhanced tolerance to stressful factors such high salinity [12]. Foliar application of GAs has been known for its role in plant stem elongation and mitigation of abiotic stress [54-60] while the same was observed in current study that endophytes producing GAs triggered the adverse effect of salinity stress.

\section{Conclusion}

P. formosus LHL10 produced many physiologically active and inactive GAs and IAA, which helped the Waito-C and Dongjin-byeo rice plants to grow well and significantly mitigated the negative impacts of salinity stress on cucumber plants. The P. formosus LHL10 also minimized the lethal effects of salt stress on cucumber leaf tissues as evidenced from EL, RWC, photosynthesis rate, nitrogen assimilation, antioxidant activity and lipid peroxidation. The cucumber plants inoculated with $P$. formosus LHL10 have ameliorated their growth by possessing lower levels of stress responsive endogenous ABA and elevated GAs contents. Current study reveals that such endophytic fungal interactions can improve the quality and productivity of economically important crop species. However, the favourable role of this fungus still needs to be investigated under field conditions.

\section{Additional material}

Additional file 1: GC/MS-SIM analysis of HPLC fractions of pure culture filtrate of $P$. formosus. The table contains retention times of various purified GAs through HPLC and GC/MS SIM data of GAs KRI values and ion numbers.

Additional file 2: GC/MS - SIM conditions used for analysis and quantification of the plant hormones. The table contains GC/MS SIM conditions used for the detection of cucumber plant's endogenous GAs and ABA.

\section{Acknowledgements}

The present research work was funded by the Eco-Innovation Project, Korean Government's R \& D program on Environmental Technology and Development.

\footnotetext{
Author details

'School of Applied Biosciences, Kyungpook National University, Daegu, Republic of Korea. ${ }^{2}$ Department of Plant Sciences, Kohat University of Science \& Technology, Kohat Pakistan. ${ }^{3}$ Department of Botany, Abdul Wali Khan University, Mardan Pakistan. ${ }^{4}$ Division of Applied Biology and Chemistry, College of Agriculture and Life Sciences, Kyungpook National University, Daegu, Republic of Korea. ${ }^{5}$ Gyeongsangbuk- Do Agricultural
}

Research and Extension Services, Division of Agriculture Environment Research, Daegu, Republic of Korea.

\section{Authors' contributions}

ALK undertook all the experimentation and manuscript preparation. $\mathrm{MH}$ and IJL participated in experimental design and supervision of the study while also participated in genomic DNA extraction and PCR analysis. SMK and YHK performed the GAs experiments while JHL and HYJ undertook microscopic analysis. All authors read and approved the manuscript.

Received: 29 July 2011 Accepted: 12 January 2012

Published: 12 January 2012

\section{References}

1. Kasuga M, Liu Q, Miura S, Yamaguchi-Shinozaki K, Shinozak K: Improving plant drought, salt, and freezing tolerance by gene transfer of a single stress-inducible transcription factor. Nature Biotech 1999, 17:287-291.

2. Hasegawa PM, Bressan RA, Zhu JK, Bohnert HJ: Plant cellular and molecular responses to high salinity. Annu Rev Plant Physiol 2000, 51:463-99

3. Xiong L, Schumaker KS, Zhu JK: Cell Signaling during Cold, Drought, and Salt Stress. Plant Cell 2002, S165-S183.

4. Munns R, Tester M: Mechanisms of Salinity Tolerance. Ann Rev Plant Bio 2008, 59:651-681.

5. Türkan T, Demiral T: Recent developments in understanding salinity tolerance. Env Exp Bot 2009, 67:2-9.

6. Gamalero E, Berta G, Glick BR: The Use of Microorganisms to Facilitate the Growth of Plants in Saline Soils. In Microbial Strategies for Crop Improvement. Edited by: Khan MS, Zaidi A, Musarat J. Berlin: Springer-Verlag; 2009:1-22.

7. Bacon CW, White JF: Microbial Endophytes Marcel Deker Inc, New York; 2000, 99-101.

8. Schulz B: Endophytic fungi: a source of novel biologically active secondary metabolites. Mycolog Res 2002, 106:996-1004.

9. Schulz B, Boyle C: The endophytic continuum. Mycolog Res 2005, 109:661-686

10. Arnold AE: Endophytic Fungi: Hidden Components of Tropical Community Ecology. In Tropical Forest Community Ecology. Edited by: Carson WP, Schnitzer SA. West Sussex: Blackwell Publishing Ltd; 2008:178-188.

11. Hyde KD, Doytong K: The fungal endophyte dilemma. Fungal Div 2008, 33:163-173.

12. Waller F, Achatz B, Baltruschat H, Fodor J, Becker K, Fischer M, Heier T, Huckelhoven R, Neumann C, Von Wettstein D, Franken P, Kogel KH: The endophytic fungus Piriformis indica reprograms barley to salt-stress tolerance, disease resistance, and higher yield. PNAS 2005, 102:13386-13391.

13. Strobel GA: Endophytes as sources of bioactive products. Microb Infection 2003, 5:535-544.

14. Khan SA, Hamayun M, Yoon HJ, Kim HY, Suh SJ, Hwang SK, Kim JM, Lee IJ, Choo YS, Yoon UH, Kong WS, Lee BM, Kim JG: Plant growth promotion and Penicillium citrinum. BMC Microbio 2008, 8:231-239.

15. Khan AL, Hamayun M, Kim YH, Kang SM, Lee JH, Lee IJ: Gibberellins producing endophytic Aspergillus fumigatus sp. LH02 influenced endogenous phytohormonal levels, plant growth and isoflavone biosynthesis in soybean under salt stress. Process Biochem 2011, 46:440-447.

16. Khan AL, Hamayun M, Kim YH, Kang SM, Lee IJ: Ameliorative symbiosis of endophyte (Penicillium funiculosum sp. LHL06) under salt stress elevated plant growth of Glycine max L. Plant Physiol Biochem 49:852-862.

17. MacMillan J: Occurrence of gibberellins in vascular plants, fungi and bacteria. J Plant Growth Reg 2002, 20:387-442.

18. Bomke C, Rojas MC, Gong F, Hedden P, Tudzynski B: Isolation and characterization of the gibberellin biosynthetic gene cluster in Sphaceloma manihoticola. Appl Environ Microbiol 2008, 74:5325-5339.

19. Rademacher W: Gibberellin formation in microorganisms. Plant Growth Reg 1994, 15:303-314.

20. Choi WY, Rim SO, Lee JH, Lee JM, Lee IJ, Cho KJ, Rhee IK, Kwon JB, Kim JG: Isolation of gibberellins producing fungi from the root of several Sesamum indicum plants. J Microbiol Biotechnol 2005, 15:22-28. 
21. Kawaide $\mathrm{H}$ : Biochemical and molecular analysis of gibberellins biosynthesis in fungi. Biosci Biotech Biochem 2006, 70:583-590.

22. Hamayun M, Khan SA, labal I, Hwang YH, Shin DH, Sohn EY, Lee BH, Na Cl, Lee IJ: Chrysosporium pseudomerdarium Produces Gibberellins and Promotes Plant Growth. J Microbiol 2009, 47:425-430.

23. Hamayun M, Khan SA, Kim HY, Chaudhary MF, Hwang YH, Shin DH, Kim IK, Lee BH, Lee IJ: Gibberellins Production and Plant Growth Enhancement by Newly Isolated Strain of Scolecobasidium tshawytschae. J Microb Biotech 2009, 19:560-565.

24. Hassan $\mathrm{HAH}$ : Gibberellin and auxin production plant root fungi and their biosynthesis under salinity-calcium interaction. Rostlinna vyroba 2002, 48:101-106.

25. Yuan ZL, Zhang CL, Lin FC: Role of Diverse Non-Systemic Fungal Endophytes in Plant Performance and Response to Stress: Progress and Approaches. J Plant Growth Reg 2010, 29:116-126.

26. Tamura K, Dudley J, Nei M, Kumar S: Molecular Evolutionary Genetics Analysis (MEGA) software version 4.0. Mol Bio Evo 2007, 24:1596-1599.

27. González L, González-Vilar M: Determination of Relative Water Content. In Handbook of Plant Ecophysiology Techniques. Edited by: Roger MJR. Netherlands: Springer; 2003:207-212.

28. Bates LS, Waldren RP, Teare ID: Rapid determination of free proline for water stress studies. Plant Soil 1973, 39:205-207.

29. Xie Z, Duan L, Tian X, Wang B, Eneji AE, Li Z: Coronatine alleviates salinity stress in cotton by improving the antioxidative defense system and radical-scavenging activity. J Plant Physiol 2008, 165:375-384.

30. Ohkawa H, Ohishi N, Yagi K: Assay of lipid peroxides in animal tissue by thiobarbituric acid reaction. Anal Biochem 1979, 95:351-358.

31. Lee IJ, Foster K, Morgan PW: Photoperiod control of gibberellin levels and flowering in sorghum. Plant Physio 1998, 116:1003-1011.

32. Shahab S, Ahmed N, Khan NS: Indole acetic acid production and enhanced plant growth promotion by indigenous PSBs. Af J Agri Res 2009, 4:1312-1316.

33. Qi QG, Rose PA, Abrams GD, Taylor DC, Abrams SR, Cutler AJ: Abscisic acid metabolism, 3-ketoacyl-coenzyme a synthase gene expression and verylong-chain monounsaturated fatty acid biosynthesis in Brassica napus embryos. Plant Physio 1998, 117:979-987.

34. Arnold AE, Henk DA, Eells RL, Lutzoni F, Vilgalys R: Diversity and phylogenetic affinities of foliar fungal endophytes in loblolly pine inferred by culturing and environmental PCR. Mycologia 2007, 99:185-206.

35. Jang SW, Hamayun M, Kim HY, Shin DH, Kim KU, Lee IJ: Effect of elevated nitrogen levels on endogenous gibberellins and jasmonic acid contents of three rice (Oryza sativa L.) cultivars. J Plant Nut Soil Sci 2008, 171:181-186

36. Kawaguchi M, Sydn K: The Excessive Production of Indole-3-Acetic Acid and Its Significance in Studies of the Biosynthesis of This Regulator of Plant Growth and Development. Plant Cell Physiol 1996, 37:1043-1048.

37. Spaepen S, Vanderleyden J, Reman R: Indole-3-acetic acid in microbial and microorganism-plant signalling. FEMS Microbio/ Rev 2007, 31:425-448.

38. Tuomi T, Ilvesoksa J, Laakso S, Rosenqvist H: Interaction of Abscisic Acid and Indole-3-Acetic Acid-Producing Fungi with Salix Leaves. J Plant Growth Regul 1993, 12:149-156.

39. Du CX, Fan HF, Guo SR, Tezuka $T$, Juan L: Proteomic analysis of cucumber seedling roots subjected to salt stress. Phytochemistry 2010, 71:1450-1459.

40. Tiwari JK, Munshi AD, Kumar R, Pandey RN, Arora A, Bhat JS, Sureja AK: Effect of salt stress on cucumber: $\mathrm{Na}+-\mathrm{K}+$ ratio, osmolyte concentration, phenols and chlorophyll content. Acta Physiol Plant 2010, 32:103-114.

41. Hari P, Boruah D, Chauhan PS, Yim WJ, Han GH, Sa TM: Comparison of Plant Growth Promoting Methylobacterium spp. and exogenous Indole-3Acetic Acid Application on Red Pepper and Tomato Seedling Development. Korean J Soil Sci Fert 2010, 43:96-104.

42. Redman RS, Kim YO, Woodward CJDA, Greer C, Espino L, et al: Increased Fitness of Rice Plants to Abiotic Stress Via Habitat Adapted Symbiosis: A Strategy for Mitigating Impacts of Climate Change. PLOSONE 2011, 6: e14823.

43. Augé RM: Water relations, drought and vesicular-arbuscular mycorrhizal symbiosis. Mycorrhiza 2004, 11:3-42.

44. Richardson AE, Barea J, McNeill AM, Prigent-Combaret C: Acquisition of phosphorus and nitrogen in the rhizosphere and plant growth promotion by microorganisms. Plant Soil 2009, 321:305-339.
45. Garg N, Manchanda G: Role of Arbuscular Mycorrhizae in the Alleviation of Ionic, Osmotic and Oxidative Stresses Induced by Salinity in Cajanus cajan (L.) Millsp. (pigeonpea). J Agron Crop Sci 2009, 195:110-123.

46. Manoharan PT, Shanmugaiah V, Balasubramanian N, Gomathinayagam S, Mahaveer $\mathrm{P}$, Muthuchelian K: Influence of AM fungi on the growth and physiological status of Erythrina variegata Linn. grown under different water stress conditions. Eur J Soil Biol 2010, 46:151-156.

47. Giri B, Kapoor R, Mukerji KG: Influence of arbuscular mycorrhizal fungi and salinity on growth, biomass and mineral nutrition of Acacia auriculiformis. Biol Fert Soils 2003, 38:170-175.

48. Jiang $M$, Zhang J: Water stress induced abscisic acid accumulation triggers the increased generation of reactive oxygen species and upregulates the activities of antioxidant enzymes in maize leaves. J Exp Bot 2002, 53::2401-2410

49. Zhang, Zhang J, Jia W, Yang J, Ismail $A M$, et al: Role of $A B A$ in integrating plant responses to drought and salt stresses. Field Crop Res 2006, 97:111-119.

50. Wang $Y$, Mopper $\mathrm{S}$, Hasenstein $\mathrm{KH}$ : Effects of salinity on endogenous ABA IAA, JA, and SA in Iris hexagona. J Chem ECo 2001, 27:327-42.

51. Jahromi F, Aroca R, Porcel R, Ruiz-Lozano JM: Influence of salinity on the in vitro development of Glomus intraradices and on the in vivo physiological and molecular responses of mycorrhizal lettuce plants. Microb Eco 2008, 55:45-53.

52. Herrera-Medina MJ, Steinkellner S, Vierheilig H, Bote JAO, Garrido JMG: Abscisic acid determines arbuscule development and functionality in the tomato arbuscular mycorrhiza. New Phytologist 2007, 175:554-564.

53. Mauch-Mani, Mauch-Mani B, Mauch F: The role of abscisic acid in plantpathogen interactions. Cur Opin Plant Bio 2005, 8:409-414.

54. Hamayun $M$, Khan SA, Khan AL, Shin JH, Lee IJ: Exogenous Gibberellic Acid Reprograms Soybean to Higher Growth, and Salt Stress Tolerance. J Agri Food Chem 2010, 58:7226-7232.

55. Iabal M, Ashraf M: Gibberellic acid mediated induction of salt tolerance in wheat plants: Growth, ionic partitioning, photosynthesis, yield and hormonal homeostasis. Env Exp Bot 2010, 10.1016/j.envexpbot.2010.06.002.

56. Shinozaki K, Yamaguchi-Shinozaki K: Gene expression and signal transduction in water-stress response. Plant Physiol 1997, 115:327-334.

57. Ueguchi-Tanaka M, Nakajima M, Motoyuki A, Matsuoka M: Gibberellin receptor and its role in gibberellin signaling in plants. Annu Rev Plant Biol 2007, 58:183-98.

58. Olszewski N, Sun TP, Gubler F: Gibberellin Signaling: Biosynthesis, Catabolism, and Response Pathways. Plant Cell 2002, 14:S61-S80.

59. Kim HY, Lee IJ, Hamayun M, Kim JT, Won JG, Hwang IC, Kim KU: Effect of prohexadione-calcium on growth components and endogenous gibberellins contents of rice (Oryza sativa L.). J Agro Crop Sci 2007 193:445-451.

60. Tuna LA, Kaya C, Dikilitas M, Higgs D: The combined effects of gibberellic acid and salinity on some antioxidant enzyme activities, plant growth parameters and nutritional status in maize plants. Environ Exp Bot 2008, 62:1-9.

61. Rodriguez RJ, White JF, Arnold AE, Redman RS: Fungal endophytes: diversity and functional roles. New Phytol 2009, 182:314-330.

62. Cheplic GP: Recovery from drought stress in Lolium perenne (poaceae) are fungal endophytes detrimental? Amer J Bot 2004, 91:1960-1968.

63. Khan AL, Hamayun M, Ahmad N, Waqas M, Kang SM, Kim YH, Lee IJ: Exophiala sp. LHL08 reprograms Cucumis sativus to higher growth under abiotic stresses. Physiol Plantarum 2011, 143:329-343.

doi:10.1186/1471-2180-12-3

Cite this article as: Khan et al:: Endophytic fungal association via gibberellins and indole acetic acid can improve plant growth under abiotic stress: an example of Paecilomyces formosus LHL10. BMC Microbiology 2012 12:3. 